\title{
RAMÓN ZORRILLA
}

\section{Algunos posibles efectos políticos del terremoto}

No es nada fácil predecir los posibles efectos, en lo social y en lo 1 político, de los movimientos telúricos de los días 19 y 20 de septiembre. A casi un mes de distancia de los hechos las heridas físicas y morales de la ciudad están aún lejos de ser resanadas.

Creemos que el desastre hizo patentes varios hechos:

1. La reacción espontánea, inmediata, de una población que fue capaz de darse ella misma una organización suficiente para iniciar los trabajos de auxilio y salvamento en una acción solidaria con gestos de desinterés y nobleza que admiraron a propios y extraños.

2. La discusión y debate en cuanto a lo apropiado o no de la intervención gubernamental en todos sus niveles, la cual frecuentemente entró en conflicto con la primera espontaneidad popular.

3. La reacción más bien tardía de los organismos no gubernamentales de la sociedad mexicana: sindicatos, cámaras, organismos representativos de la iniciativa privada, instituciones de beneficencia, partidos políticos, Iglesia jerárquica, etc. ante el desastre.

4. La reacción de otras naciones y pueblos que implicaban una inmediata solidaridad - incondicionada - de países como Alemania, Suiza, Francia, Italia, Argeliạ, las naciones de hispanoamérica, etc. Fue especialmente significativo que los Presidentes de España, Brasil, Perú, entre otros, llegasen personalmente a México, desviándose en sus respectivos viajes hacia la $\mathrm{ONU}$, para personalmente expresar - en un acto ciertamente excepcional y desusado en la historia de la diplomacia - su solidaridad ante el desastre.

5. La actitud del Gobierno de EE.UU. fue distinta. De lo poco que ha trascendido respecto de lo ocurrido en las primeras horas que siguieron al terremoto, muchos piensan que la ayuda estadounidense se condicionaba en tal forma que se hacía no aceptable. Posteriormente la visita de la esposa del Presidente Reagan se entendió como 
un gesto amistoso. Los que siguieron el evento por la televisión creyeron presenciăr más un viaje de inspección que un acto solidario y con calor humano. Las declaraciones insistentes y poco oportunas del Embajador Gavin manejando sus propias cifras sobre el desastre ayudaron a enfriarlo todo, una vez más.

Puede ilustrar un poco esa tensión la lectura de New York Times (Weekly Review) del 29 de septiembre. En la página 2 ofrece una nota sobre la visita de la Sra. Reagan y habla en ella de la conflictividad de John Gavin. En la página 7 James Reston se ocupa de la incapacidad de EU de entender a México. En la sección de correspondencia un antiguo comisionado de la ONU habla de la necesidad de que sean las Naciones Unidas las que se ocupen de coordinar toda la ayuda en casos como éste y hace referencia a un intento de parte del Gobierno norteamericano de coordinar la ayuda mundial para la ciudad y el país dañados en el terremoto del 19 de septiembre.

En otras palabras: la población - o pueblo - más allá de cualquier posición propiamente clasista fue capaz los primeros cuatro días de afrontar, casi sola, el desastre y en ausencia de una coordinación gubernamental clara e indiscutida.

Como disculpa de la acción gubernamental podría decirse que buena parte de sus instalaciones había sido también seriamente dañada.

El conjunto de organismos no estatales que de alguna manera (es en este sentido como a mi juicio, puede usarse más apropiadamente "sociedad civil") teóricamente podrían proveer los "cuadros" en una situación semejante quedó en todo caso en último lugar. Ni organismos empresariales, ni sindicatos obreros, ni partidos políticos actuaron como tales en las inmediatas tareas de auxilio.

Sobre estas bases en vista a las tres posiciones podrían aventurarse algunas previsiones a corto, a mediano y a largo plazo.

\section{A corto plazo.}

Consideramos como su término los últimos meses del año de 1987, (tiempo en el que tradicionalmente se decide la suceción presidencial dentro del PRI).

El Gobierno tendrá que acercarse mucho más a lo que comúnmente se llama "base", es decir, a esa población que despertó el 19 de sep- 
tiembre. En el nivel gubernamental puede significar una preeminencia de la clase política sobre la propiamente técnico administrativa. Un órgano de la clase política puede serlo en este tiempo la Cámara de Senadores.

En líneas generales puede pensarse también que, como nunca se hizo antes en este Gobierno, se instrumente una política que siguiendo otros modelos económicos busque, desde ahora, una mejor distribución del ingreso en la población.

Podría pensarse también otra alternativa. Endurecimiento de una línea gubernamental que se apegue a modelos del primer trienio. Creemos que esto es imposible en las circunstancias actuales y que no se contaría con la habitual pasividad de un pueblo ahora con el ánimo exacerbado y capaz de movilizarse organizadamente.

En la política internacional no creemos que haya cambios fundamentales en la línea seguida por México. Es posible que en las relaciones con EE.UU. haya de darse algún cambio que de alguna manera signifique la remoción del Embajador Gavin y su estilo diplomático.

La deuda externa tendrá que ser renegociada permanentemente y habrá una mayor oposición interna a la manera como ha sido llevada hasta ahora.

Los organismos intermedios (llámeseles "sociedad civil" o "componentes de la Constitución real") populares - organizaciones obreras, partidos políticos, Iglesia, logias masónicas, universidades, cuerpos profesionales colegiados etc. - habrán de renovar "cuadros" e inclinarse cada vez más a las necesidades de la base. No parece un tiempo apropiado para los "organismos cúpula".

\section{Mediano plazo.}

Si las instituciones políticas y sociales actuales permanecen - lo que en cuanto instituciones es de desearse - tendrá que propiciarse una mayor correspondencia y relación entre población y gobierno.

Un puente para unir las diferencias podía ser el fortalecimiento de esas instituciones intermedias e intermediarias a las que nos hemos referido más arriba como "sociedad civil". En algunos casos - Iglesia, vgr.-, esto implicaría incluso reformas constitucion ales y un posible 
entendimiento expreso y no tácito entre gobierno y organización eclesial, un concordato, por ejemplo, que pudiese combinar límites y libertad.

Esa reforma constitucional tocaría muchos otros aspectos reglamentando - no sujetando - el ejercicio de la libertad de prensa, el derecho a la información, la seguridad personal - legal, física y económica. En ellas deberían respetarse hasta el máximo la libertad y la dignidad de cada persona, pero debería evitarse que la libertad y la dignidad de unos pocos se tradujese - en la práctica - en la pérdida de esa libertad y esa dignidad para muchos.

En la política exterior es de esperarse que se dé un fortalecimiento en relaciones con los otros países y concretamente con las naciones latinoamericanas.

\section{A largo plazo.}

(Se hace inevitable recordar el "Todos estaremos muertos" de Keynes.) Podría pensarse en una sociedad mexicana fortalecida, no enajenada, en la que verdaderamente todos buscasen el bien de cada uno y cada uno el bienestar de todos.

La base de esta muy optimista previsión estaría en las cualidades de nobleza, valentía y generosidad que la población (no su clase dirigente) manifestó hace menos de un mes.

En expresión exactamente contraria a cómo funcionan las predicciones económicas (el et ceteris paribus de los economistas) esta predicción requeriría un mundo gobernado racionalmente con una organización en Naciones Unidas sabia y al mismo tiempo con fuerza suficiente que sustityyese el brutal y desencarnado juego de miedo y poder de potencias - particularmente entre Estados Unidos y la Unión Soviética - que hemos sufrido durante los últimos cuarenta años. 